\title{
RELAÇÃO DA LEITURA DO CLOROFILÔMETRO COM OS TEORES DE CLOROFILA EXTRAÍVEL E DE NITROGÊNIO NA FOLHA DE MILHO $^{1}$
}

\author{
GILBER ARGENTA ${ }^{2}$, PAULO REGIS FERREIRA DA SILVA ${ }^{2}$, CLAYTON GIANI \\ BORTOLINI ${ }^{2}$, EVERTON LEONARDO FORSTHOFER, MÉRCIO LUIZ STRIEDER ${ }^{2}$
}

\author{
Departamento de Plantas de Lavoura, Universidade Federal do Rio Grande do Sul, Porto Alegre, RS, \\ 91540-000
}

\begin{abstract}
RESUMO - Os métodos utilizados para determinar a quantidade de clorofila na folha requerem destruição de amostras de tecido e muito trabalho no processo de sua obtenção. $O$ recente desenvolvimento do medidor portátil de clorofila, que permite leituras instantâneas do teor relativo de clorofila na folha sem destruí-la, surgiu como uma nova técnica para estimar esse parâmetro. Com os objetivos de avaliar a relação entre leitura do clorofilômetro com os teores de clorofila extraível e de nitrogênio na folha em três estádios de desenvolvimento da planta de milho e de validar o uso do equipamento como parâmetro para estimar o teor relativo de clorofila na folha, conduziu-se um experimento no município de Eldorado do Sul, na região fisiográfica da Depressão Central do Estado do Rio Grande do Sul, no ano agrícola de 1999/2000. Os tratamentos constaram de dois híbridos de milho (Pioneer 32R21 e Premium) e de oito sistemas de manejo de nitrogênio em cobertura. As leituras com clorofilômetro, a extração de clorofila e a determinação do teor de nitrogênio da folha foram realizadas nos estádios de seis a sete folhas, 10 a 11 folhas e de espigamento do milho. Nos dois híbridos, as quantidades de clorofila total e das clorofilas $a$ e $b$ extraíveis foram significativamente relacionadas às leituras do clorofilômetro, nos três estádios de desenvolvimento avaliados. A leitura realizada com clorofilômetro estimou com boa precisão o teor relativo de clorofila na folha de milho, além de apresentar as vantagens de maior rapidez, menor custo e de não implicar em destruição de folhas. No entanto, o clorofilômetro não é muito preciso para avaliação do nível de $\mathrm{N}$ na planta nos estádios iniciais de desenvolvimento de milho (seis a sete folhas).
\end{abstract}

TERMOS ADICIONAIS PARA INDEXAÇÃO: Zea mays, leitura SPAD, estádios de desenvolvimento.

\section{RELATIONSHIP OF READING OF PORTABLE CHLOROPHYLL METER WITH CONTENTS OF EXTRACTABLE CHLOROPHYLL AND LEAF NITROGEN IN MAIZE}

\begin{abstract}
The methods used to determine the amount of leaf chlorophyll require destruction of tissues samples and much work in the process of its attainment. The recnt development of the portable chlorophyll meter, that makes instantaneous readings of relative chlorophyll content in leaf, without necessity of leaf destruction, appears as a new technique to estimate this parameter. With the objectives to

Recebido: 28.02.01 - Aceito: 10.07.01

1. Extraído da Tese de Doutorado, apresentada pelo primeiro autor à UFRGS, Porto Alegre, RS. Projeto parcialmente financiado pela Empresa Pioneer Sementes LTDA.

2. Departamento de Plantas de Lavoura da Faculdade de Agronomia da UFRGS. Av. Bento Gonçalves, 7712 , Caixa Postal 776. 91540-000, Porto Alegre, RS. E-mail: paulo.silva@vortex.ufrgs.br
\end{abstract}


evaluate the relation between readings of portable chlorophyll meter with of extractable chlrophyll and nitrogen contents in the leaf in three development stages of plant maize and to validate the use of this equipment as a parameter to estimate chlorophyll relative content in leaf, an experiment was conducted in the state of Rio Grande do Sul, Brazil, in the 1999/2000 growing season. Treatments consisted of two maize simple hybrids (Pioneer 32R21 and Premium) and eight nitrogen management systems. The readings with portable chlorophyll meter and the chlorophyll extration and nitrogen content determination in leaf were taken in the stages 6 to 7 leaves, 10 to 11 leaves and silking. In the two hybrids, the amounts of total chlorophyll and chlorophylls $a$ and $b$ were significantly related to the readings of portable chlorophyll meter, in the three development stages evaluated. The readings carried out with portable chlorophyll meter estimated with good accuracy the relative chlorophyll content in maize leaf. In addition, this method present the advantages to have higher performance, minor cost and not implying in leaf destruction. However, portable chlorophyll meter is not very accurate to evaluate $\mathrm{N}$ level in plant in initial stages of plant development (6 to 7 leaves).

ADDITIONAL INDEX TERMS: Zea mays, SPAD reading, development stages.

\section{INTRODUÇÃO}

Os métodos tradicionais utilizados para determinar a quantidade de clorofila na folha requerem destruição de amostras de tecido e muito trabalho nos processos de extração e quantificação. $\mathrm{O}$ recnte desenvolvimento de um medidor portátil de clorofila, que permite medições instantâneas do valor correspondente ao seu teor na folha sem destruí-la, constitui uma alternativa para estimar o teor relativo desse pigmento na folha (Dwyer et al., 1991; Argenta et al., 2001).

A determinação do teor relativo de clorofila por meio do clorofilômetro está sendo utilizado para predizer a necessidade de adubação nitrogenada em várias culturas, dentre as principais: arroz (Turner e Jund, 1991; Peng et al., 1993; Stalin et al., 2000; Balasubramanian et al., 2000); trigo (Follet et al., 1992; Reeves et al., 1993; Fox et al., 1994; Bredemeier, 1999) e milho (Piekielek e Fox, 1992; Smeal e Zhang, 1994; Blackmer e Schepers, 1995; Waskom et al., 1996; Varvel et al., 1997; Argenta et al., 2001). O teor de clorofila na folha é utilizado para predizer o nível nutricional de nitrogênio $(\mathrm{N})$ em plantas, devido ao fato de a quantidade desse pigmento correlacionar-se positivamente com teor de $\mathrm{N}$ na planta (Piekielek e Fox, 1992; Smeal e Zhang, 1994; Booij et al., 2000). Essa relação é atribuída, principalmente, ao fato de que 50 a $70 \%$ do $\mathrm{N}$ total das folhas ser integrante de enzimas
(Chapman e Barreto, 1997) que estão associadas aos cloroplastos (Stocking e Ongun, 1962).

A vantagem da medição do teor de clorofila é de não ser influenciada pelo consumo de luxo de $\mathrm{N}$ pela planta, sob forma de nitrato (Blackmer e Schepers, 1995). A baixa sensibilidade do medidor de clorofila ao consumo de luxo de $\mathrm{N}$ pelas plantas de milho é atribuída à forma com que esse nutriente se encontra na folha. Quando absorvido em excesso, acumula-se como nitrato. Nessa forma, o $\mathrm{N}$ não se associa à molécula de clorofila e, portanto, não pode ser detectado pelo medidor de clorofila (Dwyer et al., 1995). Por apresentar baixa sensibilidade ao consumo de luxo de $\mathrm{N}$, a medição efetuada pelo medidor de clorofila está sendo considerada melhor indicadora do nível desse nutriente na planta do que seu próprio teor (Blackmer e Schepers, 1995).

As leituras efetuadas pelo medidor portátil de clorofila correspondem ao teor relativo de clorofila presente na folha da planta. Os valores são calculados pelo equipamento com base na quantidade de luz transmitida pela folha, em dois comprimentos de ondas, com diferentes absorbâncias da clorofila (Minolta, 1989). As regiões de picos de absorbância da clorofila são o azul e o vermelho. As de baixa absorbância situam-se na região do verde e as de absorbância extremamente baixa na região do infravermelho 
(Hendry, 1993). Em função disso, os comprimentos de ondas escolhidos para medição do teor de clorofila, ou do índice de esverdeamento da folha, situam-se na faixa do vermelho, em que a absorbância pela clorofila é alta e não é afetada pelos carotenóides, e na do infravermelho, em que a absorbância é extremamente baixa.

$\mathrm{O}$ medidor de clorofila possui diodos que emitem luz a $650 \mathrm{~nm}$ (vermelho) e a $940 \mathrm{~nm}$ (infravermelho). A luz em $650 \mathrm{~nm}$ situa-se próxima dos dois comprimentos primários de ondas associados à atividade da clorofila (645 e $663 \mathrm{~nm}$ ). O comprimento de onda de $940 \mathrm{~nm}$ serve como referência interna para compensar diferenças na espessura ou no conteúdo de água da folha ou que sejam devidas a outros ftores (Waskom, 996). A luz que passa através da amostra da folha atinge um receptor (fotodiodo de silicone) que converte a luz transmitida em sinais elétricos analógicos. Por meio do conversor $\mathrm{A} / \mathrm{D}$, esses sinais são amplificados e convertidos em sinais digitais (Minolta, 1989), sendo usados por um microprocessador para calcular os valores SPAD (“Soil plant analysis development'), que são mostrados num visor. Os valores obtidos são proporcionais ao teor de clorofila presente na folha.

Alguns pesquisadores têm demonstrado a existência de relação entre índice de esverdeamento e teor de clorofila na folha em várias espécies de planta (Marquard e Tipton, 1987; Dwyer et al., 1995). Porém, existem poucos trabalhos que determinam a relação entre clorofila extraível e leitura do clorofilômetro em diferentes estádios de desenvolvimento do milho. Com este trabalho objetivou-se avaliar a relação entre a leitura do clorofilômetro com os teores de clorofila extraível e de nitrogênio na folha em três estádios de desenvolvimento do milho e também validar o uso do equipamento como parâmetro para estimar o teor relativo de clorofila na folha.

\section{MATERIAL E MÉTODOS}

O experimento foi conduzido a campo na Estação Experimental Agronômica da Universidade Federal do Rio Grande do Sul, localizada no município de Eldorado do Sul, região fisiográfica da Depressão Central, do Estado do Rio Grande do Sul, na estação de crescimento 1999/2000. O clima da região é classificado, segundo Köppen, como subtropical úmido, situado na transição entre os tipos fundamentais $\mathrm{cfa}_{1}$ (isoterma anual inferior a $18^{\circ} \mathrm{C}$ ) e $\mathrm{cfa}_{2}$ (isoterma anual superior a $18^{\circ} \mathrm{C}$ ) (Moreno, 1961). As temperaturas médias anual, máxima e mínima são de $19,6,24,3$ e $14,8{ }^{\circ} \mathrm{C}$, respectivamente (Ipagro, 1989). O solo da área experimental é classificado como ARGISSOLO VERMELHO Distrófico típico (EMBRAPA, 1999).

Os tratamentos constaram de dois híbridos simples de milho (Pioneer 32R21, ciclo superprecoce, e Premium, ciclo precoce) e de oito sistemas ( $\mathrm{S}$ ) de manejo de $\mathrm{N}$ em cobertura. Os sistemas de manejo $\mathrm{S} 1$ a $\mathrm{S} 5$ representam níveis de suprimento de $\mathrm{N}$ em cobertura correspondendo a aplicações de, respectivamente, $0,70,175,350 \mathrm{e}$ $525 \mathrm{~kg} \mathrm{ha}^{-1}$. Utilizaram-se diferentes sistemas de manejo de $\mathrm{N}$ para criar variabilidade nos teores de clorofila e $\mathrm{N}$ na folha de milho, e também para avaliar os níveis adequados de $\mathrm{N}$, em quatro estádios de desenvolvimento do milho, determinados com base em leituras efetuadas no clorofilômetro (ver Argenta, 2001). Os níveis de N foram aplicados em quatro épocas. No estádio de três a quatro folhas, foram aplicadas as doses de $10,25,50$ e $75 \mathrm{~kg} \mathrm{ha}^{-1}$, correspondendo, respectivamente, aos sistemas S2 a S5. O restante do $\mathrm{N}$ foi aplicado em três doses iguais, nos estádios de seis a sete folhas, 10 a 11 folhas expandidas e de espigamento. Outros três sistemas equivalentes, respectivamente, aos sistemas S3, S4 e S5, foram os tratamentos monitorados, em que as doses de $\mathrm{N}$ somente foram aplicadas quando as leituras obtidas no clorofilômetro eram inferiores ao estabelecido como adequado nos respectivos estádios de desenvolvimento da planta. As leituras no clorofilômetro correspondentes ao nível adequado de $\mathrm{N}$ utilizadas foram de 45,4, 52,1, 55,3 e 58,0, respectivamente, para os estádios de três a quatro folhas, seis a sete folhas, 10 a 11 folhas expandidas e de espigamento (ver Argenta, 2001). 
Os híbridos de milho foram implantados no dia 18 de outubro de 1999, em sistema de semeadura direta em sucessão ao consórcio de aveia preta e ervilhaca comum, com espaçamento entre linhas de $0,7 \mathrm{~m}$ e densidade de 75.000 plantas $\mathrm{ha}^{-1}$. O delineamento experimental utilizado foi de blocos casualizados, dispostos em parcelas subdivididas, com quatro repetições. Os híbridos foram locados nas parcelas principais e os sistemas de manejo de $\mathrm{N}$, nas subparcelas. Por ocasião da semeadura, foi realizada adubação em linha com 30 $\mathrm{kg} \mathrm{ha}^{-1}$ de N, $120 \mathrm{~kg} \mathrm{ha}^{-1}$ de $\mathrm{P}_{2} \mathrm{O}_{5}$ e $120 \mathrm{~kg} \mathrm{ha}^{-1}$ de $\mathrm{K}_{2} \mathrm{O}$.

As determinações realizadas foram: leitura correspondente ao teor de clorofila na folha com o clorofilômetro marca Minolta (modelo SPAD-502) e teores de clorofila extraível e de $\mathrm{N}$ total na folha. As determinações foram realizadas nos estádios de seis a sete folhas e de 10 a 11 folhas completamente desenvolvidas e no espigamento, utilizando-se cinco folhas por subparcela. Nos estádios vegetativos, as leituras com medidor de clorofila foram realizadas na $6^{\mathrm{a}}$ e $9^{\mathrm{a}}$ folhas totalmente expandidas, correspondendo, respectivamente, aos estádios de seis a sete folhas e 10 a 11 folhas expandidas. No estádio de espigamento, as leituras foram realizadas na folha-índice (primeira abaixo da espiga). Nos estádios de seis a sete folhas e de 10 a 11 folhas expandidas, os sistemas S3 a S5 não foram avaliados pelo fato de as leituras obtidas no clorofilômetro, nos tratamentos S3, S4 e S5 monitorados, serem inferiores ao estabelecido nesses estádios. Portanto, o nível de $\mathrm{N}$ aplicado nos sistemas S3 a S5 até esse estádio foi o mesmo em seus respectivos sistemas monitorados.

As leituras no medidor de clorofila (duas por folha) foram feitas em pontos situados na metade a dois terços do comprimento da folha amostrada, a partir da base, e a $2 \mathrm{~cm}$ de uma das margens da folha. Após a leitura, as folhas foram arrancadas para determinação dos teores de clorofila e de N. De cada folha (cinco por amostra), retirou-se um disco de $1,33 \mathrm{~cm}^{2}$ da região onde foram efetuadas as leituras com clorofilômetro. A extração de clorofila foi realizada com $20 \mathrm{ml}$ de etanol 99,9\% durante cinco dias. As concentrações de clorofila total e das clorofilas $a$ e $b(\mu \mathrm{g} / \mathrm{ml}$ de solução) na folha foram obtidas de acordo com as equações propostas por Knudson et al. (1977):

Clorofila $a=(13,70)\left(\operatorname{Abs}_{665} \mathrm{~nm}\right)-(5,76)\left(\mathrm{Abs}_{649} \mathrm{~nm}\right)$

Clorofila $b=(25,80)\left(\operatorname{Abs}_{649} \mathrm{~nm}\right)-(7,60)\left(\mathrm{Abs}_{665} \mathrm{~nm}\right)$

$\mathrm{O}$ restante das folhas em que foram realizadas as leituras e retirados os discos para extração de clorofila, foi seco em estufa a $\pm 60{ }^{\circ} \mathrm{C}$ até atingir em peso constante. $\mathrm{O}$ teor de $\mathrm{N}$ foi determinado de acordo com metodologia descrita em Tedesco et al. (1995).

Os dados obtidos foram submetidos à análise de correlação linear simples. Fez-se análise de regressão entre leitura do clorofilômetro e clorofila extraível e entre leitura do clorofilômetro e teor de $\mathrm{N}$ no tecido.

\section{RESULTADOS E DISCUSSÃO}

A análise de correlação simples evidenciou que, nos três estádios avaliados, as leituras do clorofilômetro correlacionaram-se positivamente com os teores de clorofila total e de clorofilas $a$ e $b$ extraíveis da folha (Tabela 1). Com relação à análise de correlação entre teor de $\mathrm{N}$ e clorofila extraível, verificou-se que apenas no estádio de seis a sete folhas o teor de $\mathrm{N}$ na folha não se correlacionou significativamente com os teores de clorofila total e de clorofilas $a$ e $b$ da folha. Nos estádios de 10 a 11 folhas expandidas e de espigamento, houve associação positiva entre essas variáveis. As leituras com o medidor portátil de clorofila correlacionaram-se positivamente com teor de $\mathrm{N}$ na folha nos três estádios avaliados. No entanto, apesar de significativa, a correlação foi menor no estádio de seis a sete folhas em relação aos outros dois estádios.

As quantidades de clorofila total e de clorofilas $a$ e $b$ extraíveis da folha foram significativamente relacionadas às leituras do clorofilômetro, nos três estádios de desenvolvimento e nos dois híbridos (Figs. 1a, 1b, 1c, 1d, 1e e ef). Os coeficientes de determinação 
variaram de 0,83 a 0,98 , de 0,80 a 0,97 e de 0,72 a 0,98 , respectivamente, para clorofila total e clorofilas $a$ e $b$. A relação clorofila $a / b$ não foi afetada nos dois híbridos pelos tratamentos com $\mathrm{N}$ nos três estádios de desenvolvimento do milho. Os valores médios dessa relação foram de 3,95 $\pm 0,09$; $3,58 \pm 0,09$ e 3,64 $\pm 0,19$, respectivamente, nos estádios de seis a sete folhas, 10 a 11 folhas e de espigamento.

A relação verificada entre leitura com medidor portátil de clorofila e teor de clorofila extraível evidencia que as leituras efetuadas com clorofilômetro estimam adequadamente o grau de esverdeamento da folha de milho, ou seja, o teor relativo de clorofila na folha, independente do estádio avaliado e do híbrido de milho.

TABELA 1 - Coeficientes de correlação simples entre os parâmetros avaliados em três estádios de desenvolvimento de milho, na média dos dois híbridos.

\begin{tabular}{ccccc}
\hline & & & & $\%$ de N \\
Parâmetros & Clorofila & Clorofila & Clorofila & $\begin{array}{c}\text { na } \\
\text { folha }\end{array}$ \\
& $a$ & $b$ & total & \\
\hline
\end{tabular}

Coeficientes de correlação linear simples (r)

\section{6 a 7 folhas}

$\begin{array}{lcccc}\text { Leitura SPAD }^{1} & 0,58^{2} & 0,54 & 0,58 & 0,35 \\ \% \text { de N } & \text { ns } & \text { ns } & \text { ns } & \text {-- }\end{array}$

10 a 11 folhas

$\begin{array}{lllll}\text { Leitura SPAD } & 0,75 & 0,77 & 0,76 & 0,61 \\ \text { \% de N } & 0,67 & 0,66 & 0,67 & --\end{array}$

Espigamento

$\begin{array}{lllll}\text { Leitura SPAD } & 0,59 & 0,64 & 0,61 & 0,59 \\ \text { \% de N } & 0,41 & 0,48 & 0,44 & --\end{array}$

${ }^{1}$ Leitura efetuada com medidor portátil de clorofila.

${ }^{2}$ Significativo a $5 \%$ de probabilidade.

${ }^{\text {ns }}$ Não significativo a $5 \%$ de probabilidade.
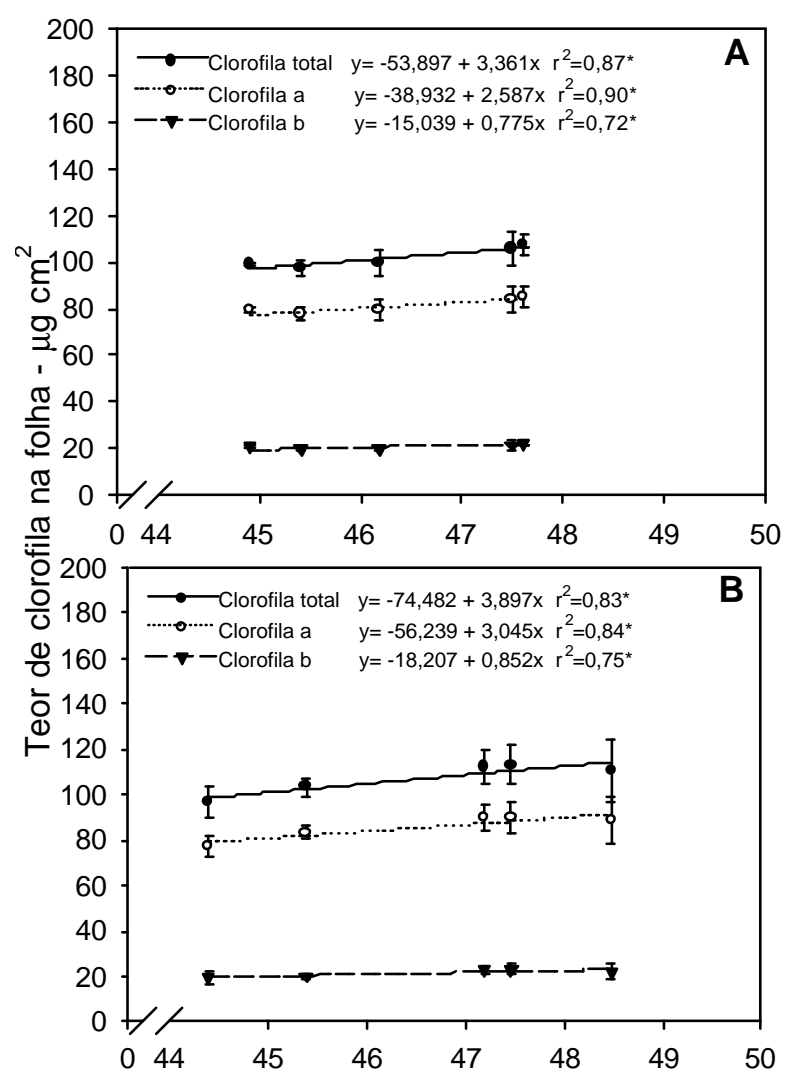

Leitura do clorofilômetro

FIGURA 1 - Relação entre teor de clorofila na folha e leitura do clorofilômetro no estádio de seis a sete folhas expandidas de milho ( $6^{\mathrm{a}}$ folha), nos híbridos Pioneer 32R21 (A) e Premium (B). Eldorado do Sul, RS, 1999/2000. Barras verticais representam desvio-padrão da média. *, significativo a $5 \%$ de probabilidade.

Portanto, as leituras efetuadas pelo equipamento podem substituir, com boa precisão, as determinações tradicionais do teor de clorofila. Avaliações realizadas na cultura do milho (Dwyer et al, 1991) e em outras espécies (Yadava, 1986; Marquardt e Tipton, 1987; Tenga et al., 1989; Dwyer et al., 1995) também constataram relação significativa entre leitura do clorofilômetro e teor de clorofila extraível da folha. 


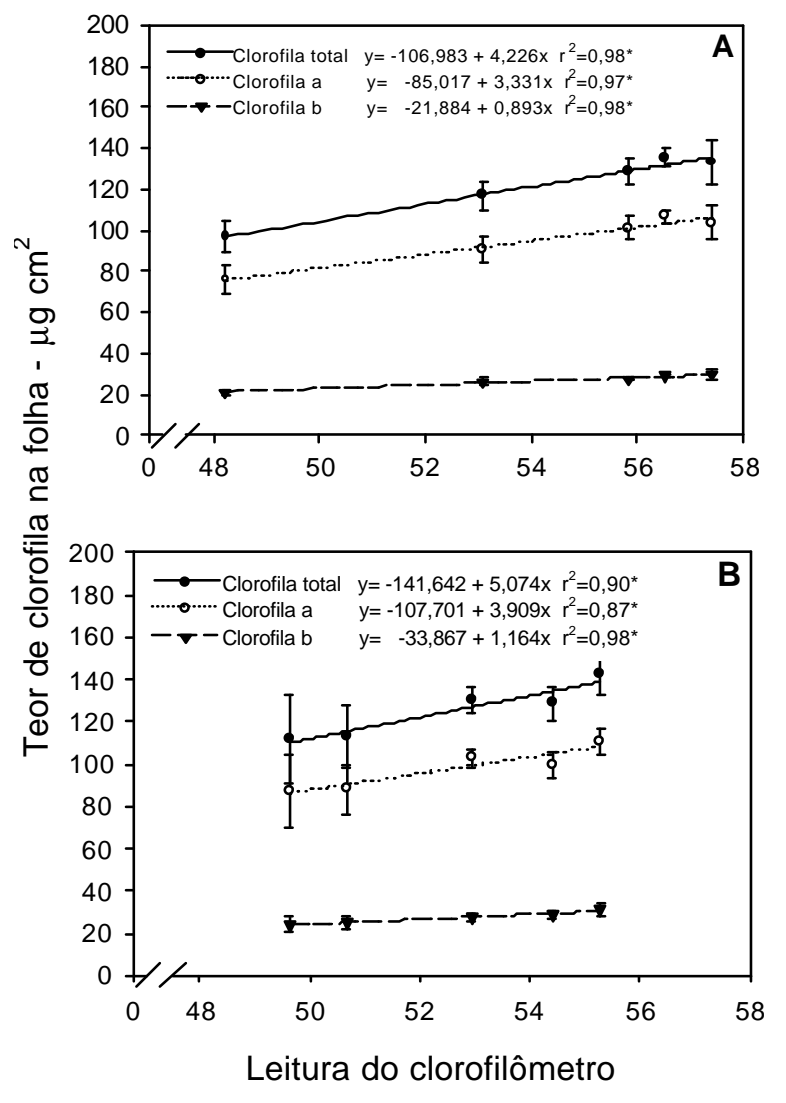

FIGURA 2 - Relação entre teor de clorofila na folha e leitura do clorofilômetro no estádio de $10 \mathrm{a}$ 11 folhas expandidas de milho ( $9^{\mathrm{a}}$ folha), nos híbridos Pioneer 32R21 (A) e Premium (B). Eldorado do Sul, RS, 1999/2000. Barras verticais representam desvio-padrão da média. *, significativo a $5 \%$ de probabilidade.

A determinação do teor de clorofila pelo clorofilômetro apresenta algumas vantagens sobre o método de extração de clorofila. Dentre essas, destacam-se: a leitura pode ser realizada em poucos minutos; o aparelho tem custo mínimo de manutenção, ao contrário de outros testes que exigem compra sistemática de produtos químicos (Piekielek e Fox, 1992); não há necessidade de envio de amostras para laboratório, com economia de tempo e dinheiro, e podem ser realizadas quantas amostras forem necessárias, sem implicar em destruição de folhas (Malavolta et al., 1997).

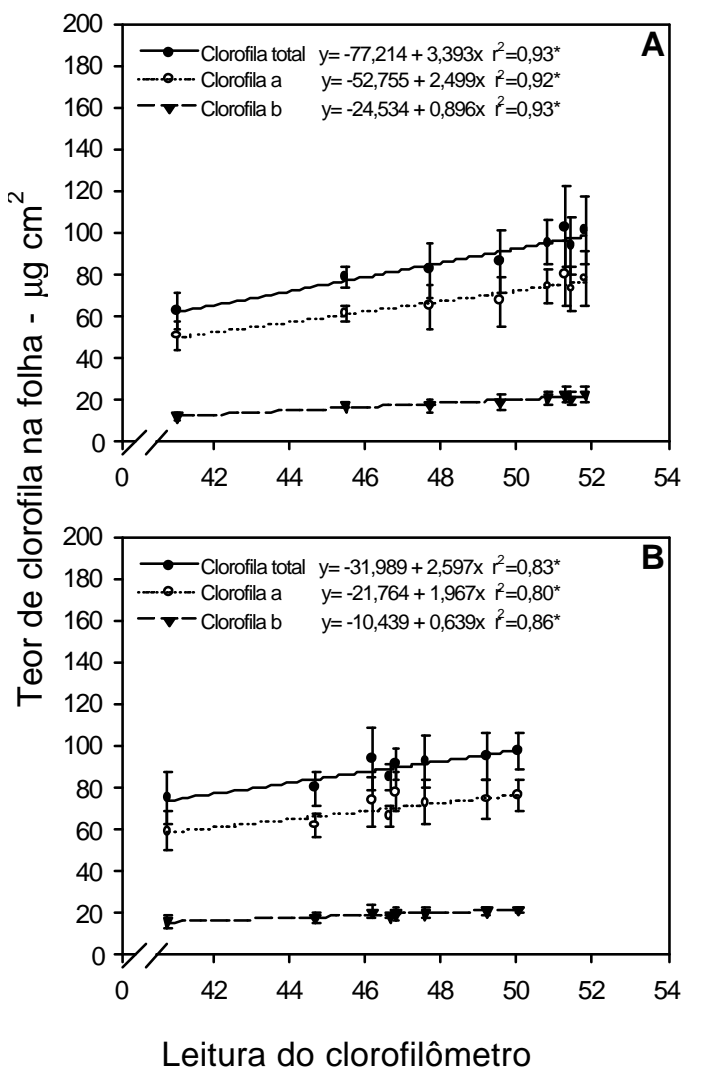

FIGURA 3 - Relação entre teor de clorofila na folha e leitura do clorofilômetro no estádio de espigamento de milho (folha índice), nos híbridos Pioneer 32R21 (A) e Premium (B). Eldorado do Sul, RS, 1999/2000. Barras verticais representam desvio padrão da média. *, significativo a $5 \%$ de probabilidade.

Ao analisar a relação entre leitura do clorofilômetro e teor de $\mathrm{N}$ na folha de milho, constatou-se que, no estádio de seis a sete folhas, não houve relação entre as duas variáveis nos dois híbridos (Figs. 4A e 4B). Já nos estádios de 10 a 11 folhas e de espigamento, o teor de $\mathrm{N}$ na folha aumentou linearmente à medida que a leitura com clorofilômetro era maior (Figs. 5A, $5 \mathrm{~B}, 6 \mathrm{~A}$ e $6 \mathrm{~B})$. 


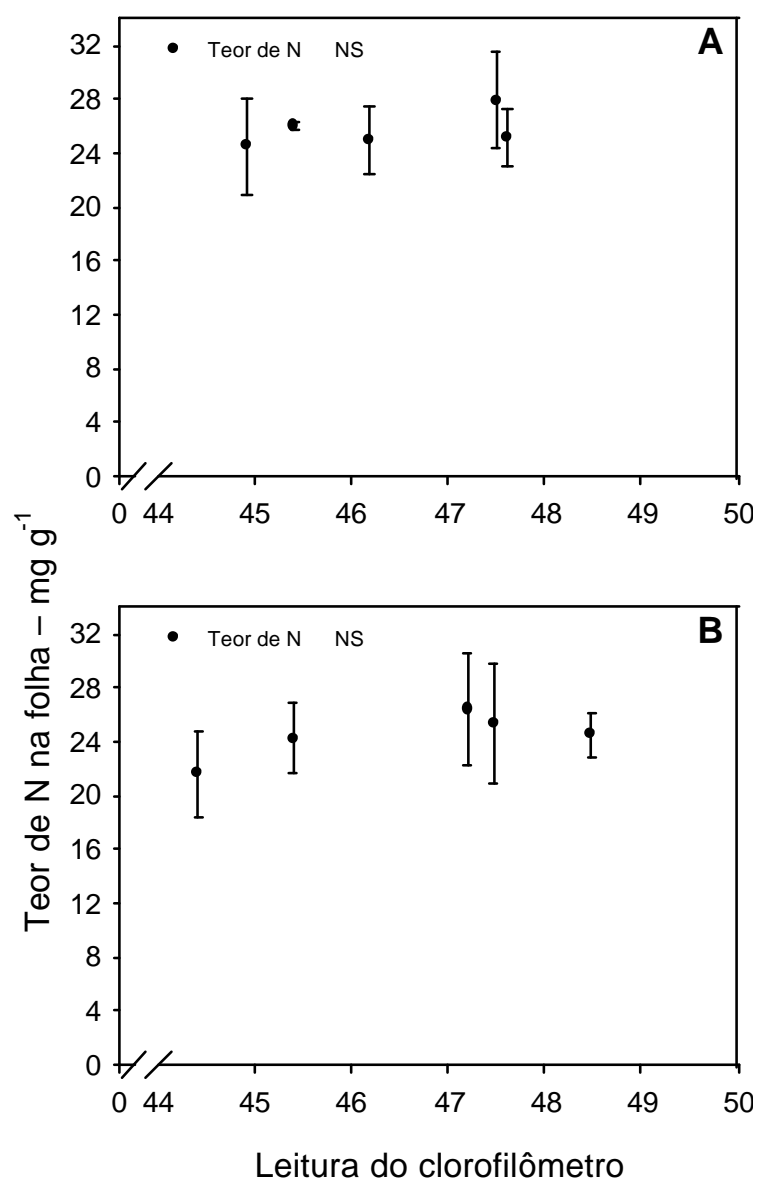

FIGURA 4 - Relação entre teor de $\mathrm{N}$ na folha e leitura do clorofilômetro no estádio de seis a sete folhas expandidas de milho ( $6^{\mathrm{a}}$ folha), nos híbridos Pioneer 32R21 (A) e Premium (B). Eldorado do Sul, RS, 1999/2000. Barras verticais representam desvio padrão da média. NS, não significativo a $5 \%$ de probabilidade.

Esses resultados confirmam os obtidos por outros pesquisadores (Schadchina e Dmitrieva, 1995; Booij et al., 2000). A falta de relação entre leitura com clorofilômetro e teor de $\mathrm{N}$ na folha (Figuras 4A e 4B) e de associação entre teor de $\mathrm{Ne}$ clorofila extraível na folha (Tabela 1) em milho, no estádio de seis a sete folhas, indicam que boa parte do $\mathrm{N}$ absorvido nessa fase é provavelmente

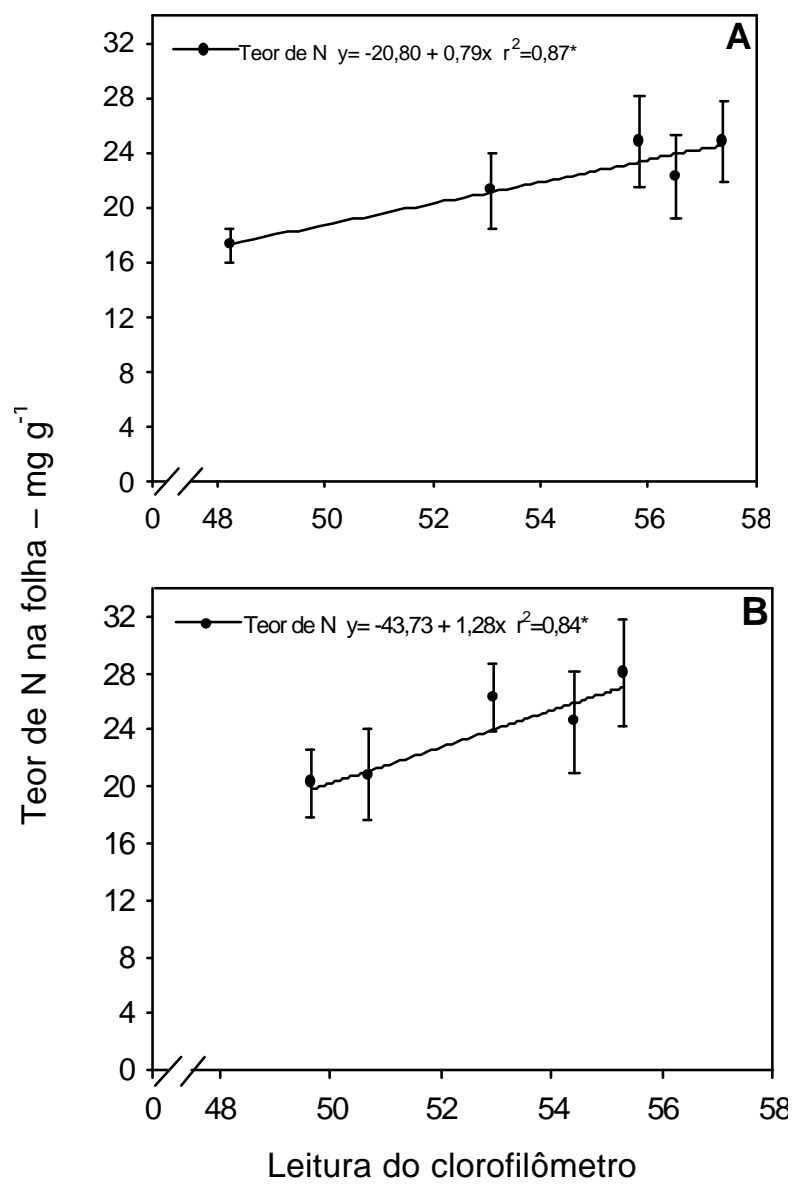

FIGURA 5 - Relação entre teor de $\mathrm{N}$ na folha e leitura do clorofilômetro no estádio de 10 a 11 folhas expandidas de milho ( $9^{\mathrm{a}}$ folha), nos híbridos Pioneer 32R21 (A) e Premium (B). Eldorado do Sul, RS, 1999/2000. Barras verticais representam desvio padrão da média. *, significativo a $5 \%$ de probabilidade.

utilizado para produção de outras estruturas na planta e não para formação de clorofila, visto que a quantidade de nitrato presente deverá ser pequena, pois o mesmo é tóxico para a planta. Portanto, as leituras efetuadas com medidor portátil de clorofila, com objetivo de verificar o nível de $\mathrm{N}$ na planta, não são muito precisas nos estádios iniciais de desenvolvimento do milho. 
Além da utilização no manejo de $\mathrm{N}$ em cereais, o clorofilômetro possui outras perspectivas de uso, como: integração de medidas de solo (teor de matéria orgânica, $\mathrm{N}$ disponível) com as leituras SPAD para refinar as recomendações de adubação nitrogenada (Waskom et al., 1996); nos modelos de simulação de crescimento (Peng et al., 1993) ou no monitoramento de mudanças no grau de esverdeamento da folha (Dwyer et al., 1991); verificação do nível de $\mathrm{N}$ em comunidade de

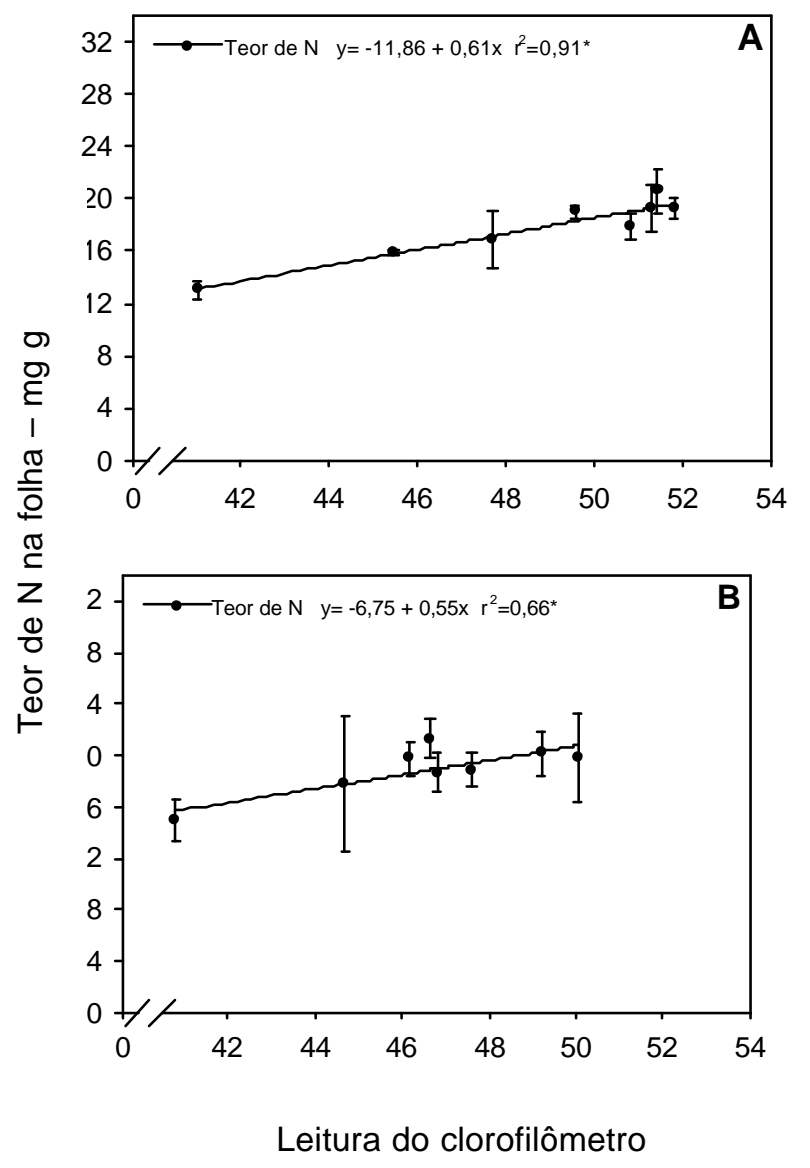

FIGURA 6 - Relação entre teor de $\mathrm{N}$ na folha e leitura do clorofilômetro no estádio de espigamento de milho (folha índice), nos híbridos Pioneer 32R21 (A) e Premium (B). Eldorado do Sul, RS, 1999/2000. Barras verticais representam desvio padrão da média. *, significativo a $5 \%$ de probabilidade. plantas através de sensoreamento remoto (Bausch e Duke, 1996); determinação do nível de $\mathrm{N}$ em culturas-testes em diferentes estádios de desenvolvimento, para melhor entendimento da dinâmica desse nutriente no sistema solo-plantaalagamento; avaliação de linhas segregantes para eficiência no uso de N; escolha de linhas eficientes no uso de $\mathrm{N}$ para identificação de genes responsáveis pela alta eficiência no uso desse nutriente (Balasubramanian et al., 2000) e seleção de linhas superiores adaptadas a situações de estresse (deficiência ou excesso de água).

\section{CONCLUSÕES}

A leitura realizada com clorofilômetro estima com boa precisão o teor de clorofila na folha de milho e apresenta as vantagens de maior rapidez, menor custo e de não implicar em destruição de folhas.

Para avaliação do nível de $\mathrm{N}$ na planta nos estádios iniciais de desenvolvimento do milho (seis a sete folhas), a leitura realizada com o clorofilômetro não é muito precisa.

\section{REFERÊNCIAS}

ARGENTA, G. Monitoramento do nível de nitrogênio na planta como indicador da adubação nitrogenada em milho. Porto Alegre, Universidade Federal do Rio Grande do Sul, 2001. 112p. Tese de Doutorado.

ARGENTA, G.; SILVA, P.R.F. da e BORTOLINI, C.G. Teor de clorofila na folha como indicador do nível de $\mathrm{N}$ em cereais. Ciência Rural, 31(3): 715-722, 2001.

BALASUBRAMANIAN, V.; MORALES, A.C.; CRUZ, R.T.; THIYAGARAJAN, T.M.; NAGARAJAN, R.; BABU, M.; ABDULRACHMAN, S. e HAI, L.H. Adaptation of the chlorophyll meter (SPAD) technology for real-time $\mathrm{N}$ management in rice: a review. International Rice Research Institute, 5:25-26, 2000. 
BAUSCH, W.C. e DUKE, H.R. Remote sensing of plant nitrogen status in corn. Transactions of the ASAE, 39:1869-1875, 1996.

BLACKMER, T.M. e SCHEPERS, J.S. Use of chorophyll meter to monitor nitrogen status and schedule fertigation for corn. Journal of Production Agriculture, 8:56-60, 1995.

BOOIJ, R.; VALENZUELA, J.L. e AGUILERA, C. Determination of crop nitrogen status using non-invasive methods. In: HAVERKORT, A.J.; MACKERRON, D.K.L. (Eds.). Management of nitrogen and water in potato production. The Netherlands, Wageningen Pers, 2000. p.72-82.

BREDEMEIER, C. Predição da necessidade de nitrogênio em cobertura em trigo e aveia. Porto Alegre, Universidade Federal do Rio Grande do Sul, 1999. 101p. Dissertação de Mestrado.

CHAPMAN, S.C. e BARRETO, H.J. Using a chlorophyll meter to estimate specific leaf nitrogen of tropical maize during vegetative growth. Agronomy Journal, 89:557-562, 1997.

DWYER, L.M.; TOLLENAAR, M. e HOUWING, L. A nondestructive method to monitor leaf greenness in corn. Canadian Journal of Plant Science, 71:505-509, 1991.

DWYER, L.M.; ANDERSON, A.M.; MA, B.L.; STEWART, D.W.; TOLLENAAR, M. e GREGORICH, E. Quantifying the nonlinearity in chlorophyll meter response to corn leaf nitrogen concentration. Canadian Journal of Plant Science, 75:179-182, 1995.

EMBRAPA. Centro Nacional de Pesquisa de Solos. Sistema brasileiro de classificação de solos. Brasília, EMBRAPA, 1999. 412p.

FOLLETT, R.H.; FOLLETT, R.F. e HALVORSON, A.D. Use of a chlorophyll meter to evaluate the nitrogen status of dryland winter wheat. Communications in Soil Science and Plant Analysis, 23:687-697, 1992.
FOX, R.H.; PIEKIELEK, W.P. e MACNEAL, K.M. Using a chlorophyll meter to predict nitrogen fertilizer needs of winter wheat. Communications in Soil Science and Plant Analysis, 25:171-181, 1994.

HENDRY, G.A. Plant pigments. In: LEA. P.J. e LEEGOOD, R.C.(Eds) Plant biochemistry and molecular biology. Great Britain, Bookcraft, 1993. p.181-196.

IPAGRO. Seção de Ecologia Agrícola. Atlas agroclimático do Estado do Rio Grande do Sul. Porto Alegre, 1989. 210p.

KNUDSON, L.L.; TIBBITTS, T.W. e EDWARDS, G.E. Measurement of ozone injury by determination of leaf chlorophyll concentration. Plant Physiology, 60:606-608, 1977.

MALAVOLTA, E.; VITTI, G.C. e OLIVEIRA, S.A . Avaliação do estado nutricional das plantas: princípios e aplicações. Piracicaba, POTAFÓS, 1997. 319p.

MARQUARD, R.D. e TIPTON, J.L. Relationship between extractable chlorophyll and an in situ method to estimate leaf greenness. HortScience, 22:1327, 1987.

MINOLTA CAMERA Co., Ltda. Manual for chlorophyll meter SPAD 502. Osaka, Minolta, Radiometric Instruments divisions. 1989. 22p.

MORENO, J.A. Clima do Rio Grande do Sul. Porto Alegre, Secretaria da Agricultura, 1961. 41p.

PENG, S.; GARCÍA, F.V.; LAZA, R.C. e CASSMAN, K.G. Adjustment for specific leaf weigth improves chlorophyll meter's estimate of rice leaf nitrogen concentration. Agronomy Journal, 85:987-990, 1993. 
PIEKIELEK, W.P. e FOX, R.H. Use of a chlorophyll meter to predict sidedress nitrogen requirements for maize. Agronomy Journal, 84:59-65, 1992.

REEVES, D.W., MASK, P.L.; WOOD, C.W. e DELANEY, D.P. Determination of wheat nitrogen status with a hand-held chlorophyll meter: influence of management practices. Journal of Plant Nutrition, 16:781-796, 1993.

SCHADCHINA, T.M. e DMITRIEVA, V.V. Leaf chlorophyll content as a possible diagnostic mean for the evaluation of plant nitrogen uptake from the soil. Journal of Plant Nutrition, 18:1427-1437, 1995.

SMEAL, D. e ZHANG, H. Chlorophyll meter evaluation for nitrogen management in corn. Communications in Soil Science and Plant Analysis, 25:1495-1503, 1994.

STALIN, P.; THIYAGARAJAN, T.M.; RAMANATHAN, S e SUBRAMANIAN, $M$. Comparing management techniques to optimize fertilizer $\mathrm{N}$ application in rice in the Cauvery Delta of Tamil Nadu, India. International Rice Research Institute, 5:2526, 2000.

STOKING, C.R. e ONGUN, A. The intracellular distribution of some metallic elements in leaves. American Journal of Botany, 49:284289, 1962.
TEDESCO, M.J.; GIANELLO, C. e BISSANI, C.A. Análise de solo, plantas e outros materiais - 2 ed. Porto Alegre: Departamento de Solos da UFRGS, 1995. 174p. (Boletim Técnico de Solos, 5)

TENGA, A.Z.; MARIE, B.A. e ORMROD, D.P. Leaf greenness meter to assess ozone injury to tomato leaves. HortScience, 24:514, 1989.

TURNER, F.T. e JUND, M.F. Chlorophyll meter to predict nitrogen topdress requeriment for semidwarf rice. Agronomy Journal, 83:926928, 1991.

VARVEL, G.E.; SCHEPERS, J.S. e FRANCIS, D.D. Ability for in-season correction of nitrogen deficiency in corn using chlorophyll meters. Soil Science Society of America Journal, 61:1233-1239, 1997.

WASKOM, R.M.; WESTFALL, D.G.; SPELLMAN, D.E. e SOLTANPOUR, P.N. Monitoring nitrogen status of corn with a portable chlorophyll meter. Communications in Soil Science and Plant Analysis, 27:545560, 1996.

YADAVA, U.L. A rapid and nondestrutive method to determine chlorophyll in intact leaves. HortScience, 21:1449-1450, 1986. 